This is the author's final, peer-reviewed manuscript as accepted for publication. The publisher-formatted version may be available through the publisher's web site or your institution's library.

\title{
Predicting congregate meal program participation: applying the extended theory of planned behavior
}

Kuei-I Lee, Rebecca Gould

\section{How to cite this manuscript}

If you make reference to this version of the manuscript, use the following information:

Lee, K., \& Gould, R. (2012). Predicting congregate meal program participation: Applying the extended theory of planned behavior. Retrieved from http://krex.ksu.edu

\section{Published Version Information}

Citation: Lee, K., \& Gould, R. (2012). Predicting congregate meal program participation: Applying the extended theory of planned behavior. International Journal of Hospitality Management, 31(3), 828-836.

Copyright: () 2011 Elsevier Ltd.

Digital Object Identifier (DOI): doi: 10.1016/j.ijhm.2011.09.019

Publisher's Link: http://www.sciencedirect.com/science/article/pii/S0278431911001630

This item was retrieved from the K-State Research Exchange (K-REx), the institutional repository of Kansas State University. K-REx is available at http://krex.ksu.edu 
Title: Predicting Congregate Meal Program Participation: Applying the Extended Theory of Planned Behavior

\title{
Authors:
}

Kuei-I Lee, PhD (Corresponding author)

$\mathrm{PhD}$ candidate (when the study was conducted)

Department of Hospitality Management and Dietetics, Kansas State University

Justin 152

Department of Hospitality Management and Dietetics

Kansas State University

Manhattan, KS 66502

785-532-2211 (office)

785-532-5522(fax)

Present affiliation and address:

Assistant Professor

Department of Hospitality Management

TungHai University

POX891, No.181 Sec3 Taichung Port Road Taichung City 40704

Taiwan, ROC

886-4-23590121\#37710 (office)

886-4-23506053(fax)

kuei521@thu.edu.tw

Rebecca Gould, PhD, RD

Director, Information Technology Assistance Center; Professor, Hospitality Management and Dietetics

214 Hale Library

Kansas State University

Manhattan, KS 66502

785-532-2298 (office)

ragou@ksu.edu

\begin{abstract}
Authorized under Title III-C of Older Americans Act, congregate meal programs provides individuals 60 years of age and older nutritious meals in senior centers. Declining participation in recent years underscores the need to understand factors that affects participation. This study applies the Theory of Planned Behavior (TPB) to explain the intention of community-dwelling older adults to participate in congregate meal programs. One additional variable, past behavior, was added to increase the prediction power of participation intention. A total of 238 participant surveys were collected and analyzed. Seven hypotheses were tested using structural equation modeling. The data fits the TPB model well. All predictor variables (attitude, subjective norm, perceived behavior control and past behavior) had a significant positive effect on participation intention. Perceived behavior control (PBC) had the greatest prediction power on intention. Based on the research findings suggestions were made to increase congregate meal program participation.
\end{abstract}


Keywords: theory of planned behavior, congregate meal program, participation intention, past behavior, salient beliefs

\section{Acknowledgement}

Thanks for the support from Kansas North-Central Flint Hills Area Agency on Aging executive director. Additionally, I sincerely appreciate the helps from all of the directors, supervisors and managers at each data collection site. Last, thanks for the Perry C. \&Virginia Peine Excellence for Aging Initiative Grant funded this research.

\section{Predicting Congregate Meal Program Participation: Applying the Extended Theory of}

\section{Planned Behavior}

\section{Introduction}

Nutrition is critical to the daily life of seniors due to its impact on their health status, physical abilities and quality of life. Monitoring nutritional status benefits older adults and positively affects society through improved health outcomes, reduced health care costs, less dependence on caregivers, decreased hospitalization stays and time required to recover from illness (Carey and Gillespie, 1995; Gallagher-Allred et al., 1996; Chima et al., 1997; Kuczmarski and Weddle, 2005).

The Older Americans Act Nutrition Program (OAANP), formerly known as the Elderly Nutrition Program consists of a range of food and nutrition services to promote older adults' physical wellness, functional independence and management of chronic disease. Authorized under Older Americans Act (OAA) Title III and supported by state agencies on aging, congregate meal programs and home-delivered meal programs are part of OAANPs. These programs provide meals to individuals who are 60 years of age or older and originated to eliminate problems with dietary inadequacy and social isolation. The legislation is intended to make these programs available to older adults who might be at risk of losing their independence (AoA, 2006a; USDHHS, AoA, 2009). 
Ponza and Wray (1990) declared older adults' perceptions about participating in congregate meal programs center around two components: 1) food (meal quality, menu variety, and meal settings) and 2) socialization (fellowship and associated recreational activities). Slezak (2000) conducted a focus group to evaluate participation in congregate meal programs. Results showed that socialization was the most frequently mentioned advantage (social interaction, social support, relief from loneliness/depression, stimulation, self-satisfaction and volunteer work). Thomas and other researchers (2011) found social interaction was primary purpose for congregate meal participants and meal consumption was secondary. Kendrick and Slezak (1989) pointed out that older adults tended to enjoy the meal more "when there was social interaction" or "than having meals provided to their homes."

Both older adult nutrition programs faced some challenges such as unsafe food cooking practices and improper delivering methods....etc. Home delivered meals require a fleet of volunteers, transportation to get the meals to older people, extensive temperature control requirements and strict adherence to food safety practices and critical control points. Foodborne illness caused by improper food-handling procedures was commonly found among home delivered meal program participants (Almanza et al, 2007). Congregate meal programs have the potential to cost less due to the setting in which the meals are served and the more controlled method of managing food safety including checking food temperature and critical control points. While socialization is a great benefit of the congregate meal environment (Sleazk, 2000; AoA, AGID, 2008a), the literature suggests that this concept might be misunderstood as a means for successful aging especially for women living alone who are mentally healthy, energetic and physically active compared with women living with a spouse (Michael et al., 2001). 
Reports from Congress about OAANP illustrate a decrease in congregate meal site participation during the period from 1980 to 2008 . The percentage of total meals served at congregate meals in relation to home delivered meals decreased from a $78 \% / 22 \%$ surplus to a 39\%/61\% deficit (O'Shaughnessy, 2004; AoA, AGID, 2008a). From 1980 to 2006, funding for home-delivered meal programs grew by $264 \%$ while funding for congregate meal programs increased by only about 43\% (O’Shaughnessy, 2004; O'Shaughnessy and Napili, 2006). The Administration on Aging (2008) reported a 17\% decrease in funds congressionally appropriated for the congregate meal programs that congress authorized through separate legislation. Declining participation and loss of funding for congregate meal programs heightens the need to recognize the factors that affect older adults' participation. Specifically, understanding nonparticipants' or infrequent participants' attitudes toward the program can point to areas in need of improvement. Table 1 shares a number of studies have examined the barriers to participating in Title III-C meal programs. However, none of these studies have analyzed the causal relationship between predictor variables and participation intention. Theory of Planned Behavior (TPB) is used in this study to explain congregate meal site participation intention. Past behavior was added as a predictor due to its significance in predicting intention and future behavior (Ouellette and Wood, 1998). 
Table 1.

Barriers to Participating in OAANP

\begin{tabular}{|c|c|c|c|c|c|}
\hline $\begin{array}{l}\text { Reasons for NON- } \\
\text { participation }\end{array}$ & $\begin{array}{l}\text { Ponza } \\
\& \text { Wray } \\
(1990)^{\mathrm{a}}\end{array}$ & $\begin{array}{c}\text { GAO } \\
(2000)^{\mathrm{a}}\end{array}$ & $\begin{array}{l}\text { Slezak } \\
(2000)^{\mathrm{a}}\end{array}$ & $\begin{array}{l}\text { Bermudez } \\
\& \text { Tucker }^{\mathrm{a}} \\
(2004)\end{array}$ & $\begin{array}{l}\text { Lee, Frongillo } \\
\text { \& Olson } \\
(2005)^{\mathrm{b}}\end{array}$ \\
\hline Don't need the program & & $\mathbf{x}$ & & & $\mathbf{x}$ \\
\hline Lack of transportation & $\mathbf{x}$ & $\mathbf{x}$ & $\mathbf{x}$ & $\mathbf{x}$ & \\
\hline $\begin{array}{l}\text { Don't like or cannot eat } \\
\text { the food }\end{array}$ & $\mathbf{x}$ & & & $\mathbf{x}$ & \\
\hline $\begin{array}{l}\text { Feel uncomfortable going } \\
\text { or don't like a stranger at } \\
\text { home }\end{array}$ & $\mathbf{x}$ & & $\mathbf{x}$ & $\mathbf{x}$ & \\
\hline $\begin{array}{l}\text { Feel uncomfortable } \\
\text { applying (age bias, } \\
\text { program for charity) }\end{array}$ & $\mathbf{x}$ & $\mathbf{x}$ & $\mathbf{x}$ & $\mathbf{x}$ & $\mathbf{x}$ \\
\hline $\begin{array}{l}\text { Unable to pay for } \\
\text { contribution }\end{array}$ & $\mathbf{x}$ & & & & $\mathbf{x}$ \\
\hline $\begin{array}{l}\text { Dislike location of } \\
\text { program }\end{array}$ & $\mathbf{x}$ & & & & \\
\hline Unaware of the program & $\mathbf{x}$ & $\mathbf{x}$ & $\mathbf{x}$ & & $\mathbf{x}$ \\
\hline Restriction on attendance & $\mathbf{x}$ & & $\mathbf{x}$ & $\mathbf{x}$ & \\
\hline $\begin{array}{l}\text { Program is full (especially } \\
\text { for home-delivered meal } \\
\text { program) }\end{array}$ & $\mathbf{x}$ & $\mathbf{x}$ & & & \\
\hline Time conflict & $\mathbf{x}$ & & $\mathbf{x}$ & & \\
\hline $\begin{array}{l}\text { Unpleasant experience } \\
\text { with a previous meal }\end{array}$ & $\mathbf{x}$ & & & & \\
\hline Language barrier & & & & $\mathbf{x}$ & \\
\hline $\begin{array}{l}\text { Dislike physical } \\
\text { environment of meal sites }\end{array}$ & $\mathbf{X}$ & & & & \\
\hline
\end{tabular}

Note: ${ }^{a}$ From congregate program participants' perspective. ${ }^{b}$ From providers' perspective.

\section{Literature review}

\subsection{Theory of Planned Behavior}

The Theory of Planned Behavior (TPB) explains the intention to act and seeks to understand the psychological determinants of behavior. It is an extension of the Theory of 
Reasoned Action (TRA) (Ajzen, 1985, 1991; Ajzen \& Madden, 1986). TRA assumes that individuals are rational and make decisions using all available information (Fishbein \& Ajzen, 1975; Ajzen and Fishbein, 1980). According to TRA, intention is a predictor for volitional behavior (Ajzen, 1988; Bagozzi \& Yi, 1989) and is affected by attitude and subjective norm (Ajzen, 1985). Limitations of the TRA are that it assumes that behavior is under total volitional control. Although a person may intend to perform a behavior, he/she may be prevented from acting because of time constraints, limited resources, and inadequate opportunities (Ajzen, 1985). For the TPB model the limitation of, "only predicting volition behavior," of the TRA has been removed and perceived behavioral control (PBC) added to measure non-volitional behavior. PBC refers to an individuals' perception of the ease or difficulty of performing a behavior (Ajzen, 1991) and directly affects intention and behavior. TPB meta-analysis studies demonstrate that PBC, when added to the TRA model, increases the predictive power of intention (Ajzen and Madden, 1986; Ajzen, 1991; Godin \& Kok, 1996; Hausenblas et al., 1997; Warburton \& Terry, 2000; Albarracin et al., 2001; Armitage \& Conner, 2001; Hagger et al., 2002). A person's intention to perform a behavior or complete an actual behavior is predicted by attitude, subjective norm, and PBC. Intention can predict behavior if no change in intention occurs before performing the behavior.

Congregate meal programs can be categorized as a health behavior function. The TPB has been adapted for several health related studies. For example, the TPB was used with older populations to explore intention to exercise (Courneya, 1995; Gretebeck, 2000; and see Hagger et al., 2002 meta-analysis), predict dairy product consumption (Kim, Reicks, \& Sjoberg, 2003), make volunteer decisions (Warburton \& Terry, 2000) and examine the use of assistive devices (Roeland, Oost, Depoorter \& Buysse, 2002). 
Hagger et al. (2002) conducted a meta-analysis of TRA and TPB to assess physical activities; more than half of these studies were conducted with an older adult sample. Courneya (1995) examined the relationship of TPB among predictor variables, intention and physical activity behavior in 288 seniors. Results showed that attitude, subjective norms and PBC had significant predictive power over intention. Courneya, Nigg and Estabrooks (1998) measured the physical activities of 13 seniors over three years. Here, the subjective norm (pressure from important individuals) appeared to be more relevant in influencing older adults to be physically active. Gretebeck (2000) compared the TRA and the TPB in predicting the physical activities of older adults and found that the predictor variables in TPB better explained differences than TRA $\left(\mathrm{R}^{2}=.59\right.$ vs. $\left.\mathrm{R}^{2}=.46\right)$. Including PBC can increase accuracy in predicting physical activity behavior.

A study applying TPB to predicting dairy product consumption among older adults showed that attitude and $\mathrm{PBC}$ were great predictors for intention, while subjective norm was not (Kim et al, 2003). One possible reason for the lack of a relationship is that in this case, older adults depend on their own beliefs and judgment.

Roelands et al. (2002) study used 491 community-dwelling elderly between 70 to 89 years of age to measure the use of assistive devices. Self-efficacy (self-efficacy was used in this study instead of PBC) $(\beta=.47, p \leq .001)$ showed a stronger significant prediction power for intention than attitude $(\beta=.17, p \leq .001)$ and subjective norm $(\beta=.01, p \leq .05)$. Warburton and Terry (2000) tested a revised TPB to predicting the intention to volunteer among seniors. The subjective norm, $\mathrm{PBC}$ and moral obligation predicted intention. Attitude was a mediator for moral obligation. 
Barriers or controls such as lack of transportation and time constraints affect program participation (Ponza and Wray, 1990; GAO, 2000; Slezak, 2000; Bermudez and Tucker, 2004). Although TPB is generally applicable to human behaviors, it must be modified and alternatives provided to explain some human behaviors (Oh and Hsu, 2001). In this study, the role of past behavior was incorporated to test the causal relationship between predictor variables and intention because unpleasant previous participation experiences could affect participation intention (Ponza and Wray, 1990).

\subsection{Beliefs Based Measures of TPB}

Originally, the beliefs based construct was adopted from expectancy-value theory (Fishbein and Ajzen, 1975). A person's decision to perform or not to perform behavior is based on relevant beliefs. Beliefs are important in both TRA and TPB because they provide the cognitive and affective foundations for attitudes, subjective norms, and PBC (Ajzen, 2002). Three belief based measurements of the TPB include behavioral beliefs, normative beliefs, and control beliefs. Behavioral beliefs refer to the subjective probability that an individual's behavior will yield a specific consequence (Ajzen and Fishbein, 1980).

Normative beliefs focus on the likelihood that influential individuals or groups would approve or disapprove of the behavior (Ajzen and Madden, 1986). Control beliefs focus on factors that facilitate or inhibit performance of the behavior and the perceived power of these factors (Ajzen, 1985). PBC is a function of control beliefs, which are the individual's perception of the ease or difficulty of performing the behavior (Ajzen, 1991).

\subsection{Past Behavior}

Bloom (1964) first revealed that past behavior is a predictor of current behavior. Ajzen (1991, p.199) stated, “ Theory of planned behavior is, in principle, open to the inclusion of 
additional predictors if it can show they capture a significant proportion of the variance in intention or behavior after the theory's current variables have been taken into account." Conner and Armitage (1998) reviewed six additional variables for TPB. The author reported that past behavior is one additional predictor variable that strongly affects intention and future behavior. Past behavior explained an additional $7 \%$ of the variance in intention after taking into account attitude, subjective norm, and PBC. Ouellette and Wood's (1998) meta-analyses concluded, in 19 out of 22 studies, past behavior was a significant factor affecting behavior intention after controlling for attitude and subjective norm.

participate in congregate meals. The specific objectives include (a) identify salient beliefs about participating, (b) determine appropriate questions to measure the factors associated with the TPB, (c) examine the construct validity of an extended TPB model, (d) identify the effects of salient beliefs on attitudes, subjective norms, and perceived behavior control, (e) test the causal relationship between the predictor variables (attitude, subjective norm, perceived behavior control and past behavior) and intention, and (f) investigate the extent to which predictor variables influence program participants' intention.

Seven hypotheses were proposed 1) behavioral beliefs are positively associated with attitudes; 2) normative beliefs are positively associated with subjective norms; 3) control beliefs are positively associated with perceived behavior control; 4) attitude toward participation has a positive effect on participation intention; 5) subjective norms about program participation have a positive effect on participation intension; 6) perceived behavior control over program participation has a positive effect on participation intention; 7) past behavior has a positive effect on participation intention. 


\section{Methods}

\subsection{Population and Sample}

The population included (a) the community-dwelling older adults, (b) who are 60 years of age or older, and (c) reside in Kansas North Central Flint Hills (NCFH) region. The region spans 18 counties and includes 45 nutrition programs served at nutrition sites or senior centers. The region was chosen because of proximity to the research site and funding availability.

\subsection{Questionnaire Development}

Questionnaire development included a review of literature and completion of an elicitation study. The elicitation study was conducted based on suggestions from Ajzen and Fishbein (1980) who surmise that a new set of beliefs and salient referents must be elicited for each new context, population, and behavior. The overview of process included 1) elicitation study, 2) initial questionnaire development, 3) expert panels, 4) pilot test and 5) refine final questionnaire.

\subsubsection{Salient Beliefs}

The elicitation study was undertaken to define salient belief measures. The elicitation study included focus group interviews $(\mathrm{N}=39)$ and salient beliefs analysis $(\mathrm{N}=43)$. For the focus group interviews, nine open-ended questions (Francis et al., 2004) were used to elicit behavioral, normative, and control belief themes. The moderator facilitated the discussion and a research assistant took notes. The focus group discussion was tape recorded. Content analysis was used to establish themes among responses based on field notes and recorded tape. From the focus group data, five common salient beliefs were then selected from each belief category as suggested by Van der Pligt and Eiser (1984). Participants were asked to choose the five belief items most salient to them from behavioral beliefs, normative beliefs, and control beliefs. 
The five salient behavioral beliefs included convenience, social interaction, low-price, nutritious and balanced meals, and less waste. Two questions were included for each of the five belief themes. First, the perceived likelihood of the behavior was measured by asking respondents "eating meals at the senior center would...." to rate each behavioral belief on a 5point rating scale ranging from very unlikely (1) to very likely (5). Second, outcome evaluation was assessed by the statement "there are a number of possible benefits of eating in the senior center. From 1 (not a real benefit) to 5 (very real benefit to me), rate each possible outcome below". Consequently, the perceived likelihood of the behavior and the outcome evaluation were multiplied together (e.g., behavioral beliefs X outcome evaluation) to become one of the measurement variables of the behavioral belief factor.

Subjective norm included the normative beliefs multiplied by the respondent's motivation to comply. Five referent groups (family members, friends, neighbors, cooks at the meal sites, and health professionals) were identified through the elicitation study. Respondents were asked to evaluate the statement, "what do you believe each of the groups below thinks about you eating meals at the senior center?" on 5-point scale ranging from definitely should not (1) to definitely should (5). Respondents' motivation to comply was assessed by the statement "Each of groups below may have different views about whether you should eat at the senior center and how likely would you be to take their advice?" The rating scale was very unlikely (1) to very likely (5).

Control beliefs were drawn from the elicitation of integrated inhibitors and facilitators for program participation. The five most salient control beliefs for participating in congregate meal programs were (a)activities at senior centers, (b)available transportation, (c)welcoming culture at the senior center, (d)lack of motivation and ability to cook at home, and (e)poor weather. Each measurement variable is the control belief multiplied by its perceived power or the ease or 
difficulty of performing the behavior. The question preceding the control beliefs was "how easy is it for you to eat meals in the senior center if ....."; answers were measured on a 5-point Likert scale ranging from very difficult (1) to very easy (5). The question for perceived power was "how likely are you to eat meals at the senior center if...." rated on 5-point scale ranging from very unlikely (1) to very likely (5).

\subsubsection{Predicting Variables and Intention}

The statement "Eating meals at the senior center during the week is....." followed by the semantic differential scales including worthless/valuable, useless/useful, harmful/beneficial, unpleasant/pleasant, unhealthy/healthy, boring/interesting, and bad/good was used to measure attitude.

Subjective norm was measured with two questions "Most people who are important to me think I should eat meals at the senior center" and "When it comes to eating meals at the senior center, I would follow the advice of others who are important to me." A five-point rating scale was used, ranging from strongly disagree (1) to strongly agree (5).

Six questions were used to measure PBC by assessing the person's self-efficacy and beliefs about control in performing the behavior (Ajzen, 2002). Three questions measured selfefficacy; one example question was "whether or not I eat meals in the senior center is entirely up to me" using a 5-point scale ranging from strongly disagree (1) to strongly agree (5). The other three questions measured beliefs about control. Measurement items like "I am confident that I can eat meals in the senior center" used the same scale.

Past behavior was measured by asking about frequency of program participation, similar to questions used in earlier research (Ouellette and Wood, 1998; Oh and Hsu, 2001; Lam and 
Hsu, 2004). Three questions measured intention; one example was "I intend to eat meals at the senior center in the future" with scores from strongly disagree (1) to strongly agree (5).

A draft of the questionnaire was reviewed by six experts that suggested modifications to the font size and the rephrasing of ambiguous sentences to enhance the questionnaires' readability and simplicity. The instructions for administering the survey were modified to increase clarity. A pilot test, with 63 seniors from two senior centers and one retirement group, was conducted to assess measurement reliability. The Cronbach's alpha for each construct was from .73 to .92 , which surpassed the recommended satisfaction level of .70 (Nunnally and Bernstein, 1994) except for PBC. To improve the reliability of the PBC construct, one question was rephrased, reverse scales were eliminated, and two more questions were included.

The final instrument contained two sections: (a) factors affecting senior meal program participation intention and (b) demographic information. The complete instrument showed in Appendix A. The term "senior meal programs" was substituted for "congregate meal programs" at the suggestion of the Area Agency on Aging executive director because the former conveys a more positive image. Ajzen (2006) suggested that researchers must explicitly describe the behavior for their respondents, and the goal behavior should be defined in terms of its target, action, context, and time at the beginning of the questionnaire. All the measures in the questionnaire should follow the same level of generality (Francis et al., 2004). In this study the congregate meal program participation was specifically stated as "participating (action) in senior meal program (target) in central dining areas (context) during weekday lunchtime (time)"; this description was included in the cover letter. To reduce the potential bias of forced selection, an option of "I don't know" was included for each question except for demographics. 


\subsection{Data Collection}

Researchers contacted the North Central Flint Hills (NCHF) AAA executive director to explain the purposes of the study. The director provided useful suggestions and data collection advice, and recommended effective strategies to gather input from older adults. Before distributing the questionnaires, approval was received from managers and group leaders of each site. Data collection sites included a senior fair, senior centers, senior living facilities, the YMCA, and a monthly meeting of retirees. The sites spanned nine counties covering half of the NCFH region. Surveys not satisfying collection criteria were excluded. From these sites 358 surveys were collected.

Some steps were employed to handle actual missing data. The first step was calculating each individual's composite mean score for each factor by using valid data and replacing the composite mean for the missing data. If more than half the total indicators under one factor were missing, the missing value was not replaced. Next, the total amount of actual missing data that could not be replaced was combined with the number of "I don't know" answers in each case. If the case had more than five missing data points, including actual missing data without replacement and "I don't know" responses, the entire survey was eliminated from the sample. According to Hair et al. (2006), missing data less than 10\% (5 missing values in this study) for an individual case can generally be ignored. The net result was 248 completed surveys.

\subsection{Data Analysis}

Some steps were employed to handle actual missing data. The first step was calculating each individual's composite mean score for each factor by using valid data and replacing the composite mean for the missing data. If more than half the total indicators under one factor were missing, the missing value was not replaced. Next, the total amount of actual missing data that 
could not be replaced was combined with the number of "I don't know" answers in each case. If the case had more than five missing data points, including actual missing data without replacement and "I don't know" responses, the entire survey was eliminated from the sample. According to Hair et al. (2006), missing data less than 10\% (5 missing values in this study) for an individual case can generally be ignored. The net result was 248 completed surveys.

The data were coded and verified by two different individuals to reduce data entry error. Statistical analysis was performed using SPSS for Windows 13.0 (SPSS Inc., Chicago) and AMOS 4.0 (Smallwater Corp, 1999). Descriptive statistical analysis was used to assess the nature of the data and to develop a profile of the respondents. A two-step modeling approach suggested by Anderson and Gerbing (1988) was used for data analysis. In the first step, confirmatory factor analysis (CFA) was used to assess measurement model fit and re-specified the model. Using CFA assured that each construct was defined by at least two indicators, and each indicator was intended to be an indicator only for a specific construct. Because there was only one indicator for past behavior, CFA did not include the factor of past behavior. The validity and reliability of measurement for factors were tested before performing Structural Equation Modeling (SEM). The structural model uses paths which relate independent to dependent variables and these paths are based upon theoretical considerations. The situation where one dependant variable becomes an independent variable in other dependence relationships can be handled without problem. If the measurement model resulted in proper fit and was appropriate to apply, the next step in the data analysis was conducted. The second step was to evaluate the structural model by measuring overall model fit and to determine the causal relationships between factors. The overall fit of the proposed model was assessed using goodness-of-fit indices as recommended by Byrne (2001) and Hair et al. (2006). Standardized 
path coefficients were used to test the hypothesized path among constructs proposed in the structure model.

\section{Results}

\subsection{Data Screening}

The data were screened before being analyzed, and assumptions were checked to ascertain any violations of multivariate analysis. The univariate test of normality examined the normal distribution of each variable. The factor "attitude" had a pattern of severe negative skewness. The inverse transformation was performed to achieve the best results. The multivariate outlier was detected using Mahalanobis distance. The Mahalanobis distance is a great tool to determine the distance of a case from the centroid and defined by the correlated independent variables. Ten cases were found significant (Mahalanobis'D (34)>65.25, p<.001) and removed. As a result the final sample included 238 completed surveys.

\subsection{Descriptive Statistics}

Among the total 238 usable samples, 69 were males (29\%) and 169 were females (71\%). The mean age of respondents was 77 years; approximately $80 \%$ of participants were 70 or older. Forty-five percent of the respondents were married and $41 \%$ were widowed. Half of participants lived alone. Three percent lived with children. Ninety-eight percent were Caucasian. Most participants (61\%) had a high school education, $8 \%$ had an associate's degree, and $21 \%$ had a bachelor's degree or higher. Only 21 participants (9\%) reported he/she had never participated in congregate meal programs. On the other hand, $70(29 \%)$ were frequent participants ( 5 times or more a week). More than half (55\%) earned an annual household income more than $\$ 20,000$. Forty participants did not answer the question, possibly because they felt the question was intrusive. Table 2 provides demographic characteristics of the sample population. 
Table 2.

Demographic Characteristics of Respondents

\begin{tabular}{|c|c|c|}
\hline Characteristic & Frequency & Percent (\%) \\
\hline \multicolumn{3}{|l|}{ Gender $(\mathrm{N}=238)$} \\
\hline Male & 69 & 29.0 \\
\hline Female & 169 & 71.0 \\
\hline \multicolumn{3}{|l|}{ Age $(\mathrm{N}=238)$} \\
\hline $60-69$ & 49 & 20.6 \\
\hline $70-79$ & 104 & 43.7 \\
\hline $80-89$ & 70 & 29.4 \\
\hline Over 90 & 15 & 6.3 \\
\hline \multicolumn{3}{|l|}{ Marital status $(\mathrm{N}=237)$} \\
\hline Single & 14 & 5.9 \\
\hline Married & 106 & 44.7 \\
\hline Widowed & 97 & 40.9 \\
\hline Divorced & 20 & 8.4 \\
\hline \multicolumn{3}{|l|}{ Living arrangement $(\mathrm{N}=238)$} \\
\hline Living alone & 118 & 49.6 \\
\hline Living with a spouse & 106 & 44.5 \\
\hline Living with your child/children & 8 & 3.4 \\
\hline other & 6 & 2.5 \\
\hline \multicolumn{3}{|l|}{ Race $(\mathrm{N}=238)$} \\
\hline Caucasian & 232 & 97.5 \\
\hline Hispanic & 1 & 0.4 \\
\hline African Americans & 1 & 0.4 \\
\hline Asian/Pacific Islander & 2 & 0.8 \\
\hline American Indian/ Native Alaskan & 1 & 0.4 \\
\hline Other & 1 & 0.4 \\
\hline \multicolumn{3}{|l|}{ Education $(\mathrm{N}=237)$} \\
\hline Elementary & 7 & 3.0 \\
\hline Some high school & 12 & 5.1 \\
\hline High school graduate & 145 & 61.2 \\
\hline Associate degree & 20 & 8.4 \\
\hline Bachelor's degree & 27 & 11.4 \\
\hline Master's degree or higher & 26 & 11 \\
\hline \multicolumn{3}{|l|}{ Frequency of past participation experience $(\mathrm{N}=238)$} \\
\hline None & 21 & 8.8 \\
\hline Only ate the meal one time & 15 & 6.3 \\
\hline Less than or equal to one time per month & 33 & 13.9 \\
\hline 2-3 times per month & 24 & 10.1 \\
\hline 1 time per week & 14 & 5.9 \\
\hline 2 times per week & 13 & 5.5 \\
\hline 3 times per week & 26 & 10.9 \\
\hline 4 times per week & 22 & 9.2 \\
\hline 5 times or more per week & 70 & 29.4 \\
\hline
\end{tabular}




\begin{tabular}{l|r|r}
\hline Household income $(\mathrm{N}=198)$ & 23 & 11.6 \\
$\$ 10,000$ or less & 43 & 21.7 \\
$\$ 10,001-\$ 15,000$ & 24 & 12.1 \\
$\$ 15,001-\$ 20,000$ & 27 & 13.6 \\
$\$ 20,001-\$ 25,000$ & 17 & 8.6 \\
$\$ 25,001-\$ 30,000$ & 15 & 7.6 \\
$\$ 30,001-\$ 35,000$ & 9 & 4.5 \\
$\$ 35,001-\$ 40,000$ & 40 & 20.2 \\
$\$ 40,001$ or more & 9 & \\
\hline
\end{tabular}

A National Survey of Older Americans Program (AoA, AGID, 2008b). The gender distributions for both samples were similar. In the current study, however, the population was younger, married, Caucasian, and had more education than the national sample. This study was conducted in Kansas where 94\% of people who are age 65 and over are Caucasian (U.S. Census Bureau, 2000) and explains the higher percentage of Caucasians compared to the national sample (94\% vs. 87\%) (U.S. Census Bureau, 2000). Half of the respondents lived alone for both populations. The number of respondents who participate in congregate meal program five times or more per week was higher in the current study than in the national sample (29\%versus $21 \%)$. Data were collected from senior centers which increase the chances to recruit program participants. The national sample was randomly generated via telephone interviews that improved generalizability. The national sample had more seniors from low income households.

Further analyses eliminated the potential bias caused by invalid cases and missing data. There were no significant differences between two groups in the demographic variables such as gender $\left(\chi^{2}=1.48, \mathrm{p}=.22\right)$, age $\left(\chi^{2}=.06, \mathrm{p}=.1 .00\right)$, martial status $\left(\chi^{2}=1.00, \mathrm{p}=.80\right)$, living arrangement $\left(\chi^{2}=2.40, p=.49\right)$, race $\left(\chi^{2}=4.84, p=.44\right)$, education level $\left(\chi^{2}=2.26, p=.89\right)$ and income $\left(\chi^{2}=4.3, p=.75\right)$. However, significant differences were found between two groups in participation frequency $\left(\chi^{2}=27.34, p=.001\right)$. Possible reasons might be unfamiliarity with or confusion about some questions. Those who had never participated in the program or 
participated only once might not understand some of the questions. For example, if they didn't know how the referent group might influence their personal intention to eat meals at the center, their answers to subjective norm might be "I don't know" or they might leave the question blank. Regular program participants answered the question based on past history. Therefore, missing data is not a serious issue because the total sample had similar demographics.

\subsection{Model Evaluation}

\subsubsection{Measurement Model}

Confirmatory factor analysis (CFA) was used to identify whether the measurement items reliably estimated constructs in this study. Seven constructs were included. Past behavior was excluded because there was only one indicator for this construct. Construct validity was measured using CFA. Based on Hair et al. (2006), construct validity assesses the set of measurement items that reflect the theoretical latent constructs and is designed to accurately measure corresponding constructs. The construct validity included convergent validity and discriminant validity. Convergent validity means that the items that are indicators of a specific construct should share a high proportion of the common variance. Factor loadings, Average Variance Extracted (AVE) and construct reliability value measures convergent validity. In this study, the standardized factor loadings for each item were all significant at $\mathrm{p}<.001$ and were equal to or more than .50 . The cutoff point of .70 for the composite reliability value was determined based on the recommendations of Hair et al. (2006). AVE should be .50 or more, indicating an adequate convergence (Fornell and Larcker, 1981; Hair et al., 2006). In this study, all constructs achieved the required level. Discriminant validity was used to check construct distinction from other constructs. It is measured by comparing the AVE and the square of the correlation between the two factors. If AVE is more than the squared correlation, this indicates 
an acceptable discriminate validity (Hair et al., 2006). The AVE of each construct was higher than its corresponding square correlation with other constructs. The construct of this study satisfied discriminate validity.

The overall model fit of the measurement model was evaluated through AMOS output. The Chi-square $\left(\chi^{2}\right)$ statistic showed the measurement model was significant $\left(\chi^{2}=1059.439\right.$, $\mathrm{df}=471, \mathrm{p}<.001)$. Other model fit indices used included comparative fit index (CFI), TuckerLewis index (TLI), normed fit index (NFI), and root mean square error approximation (RMSEA). The goodness-of-fit indices showed the data were all at an acceptable level and the measurement model fit moderately well $\left(\chi^{2} / d f=2.25, \mathrm{CFI}=.979, \mathrm{TLI}=.975, \mathrm{NFI}=.963\right.$, RMSEA=.073) (Table 3). 
Table 3.

Factor loading, construct reliability, and AVE

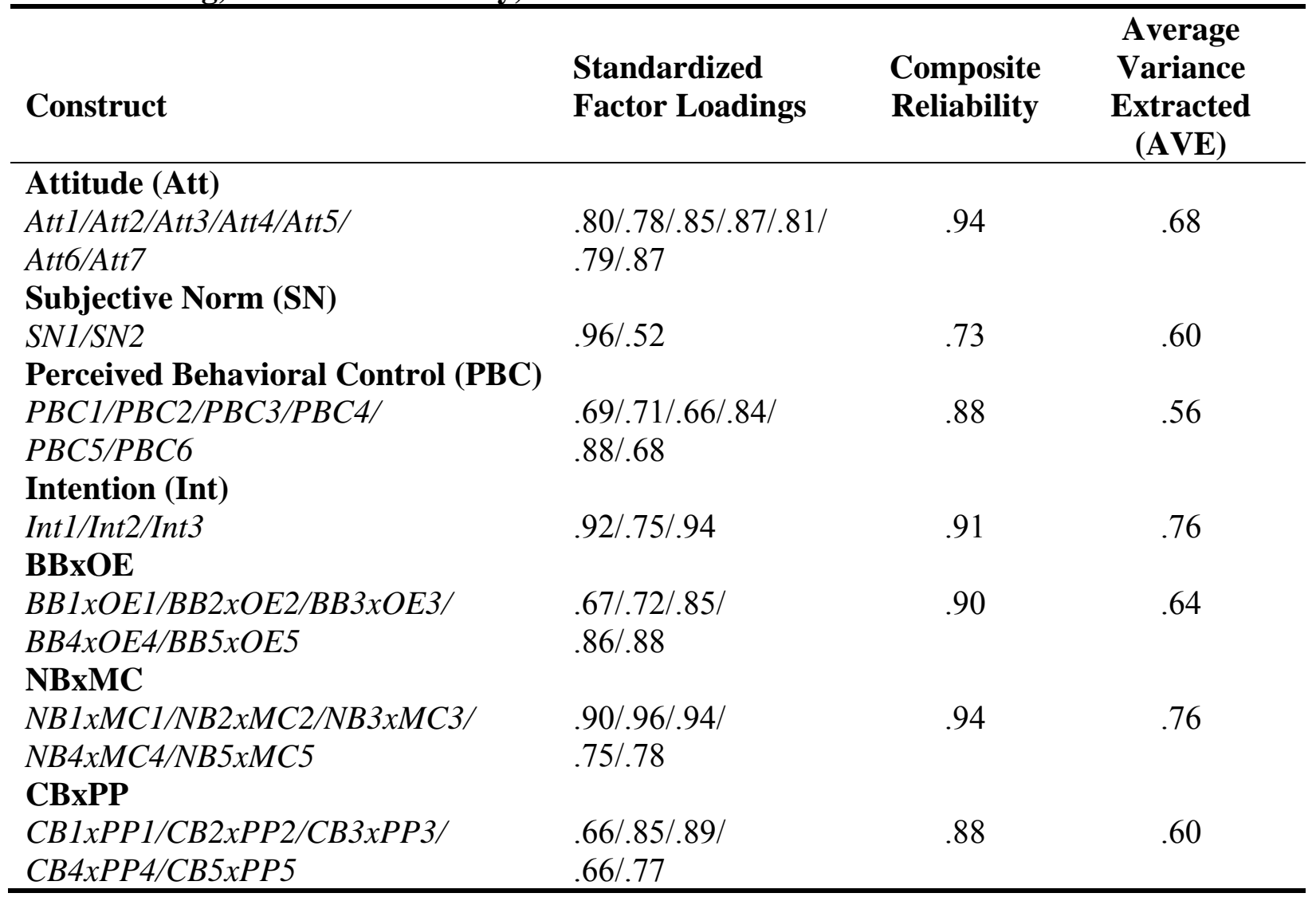

Note: $\mathrm{BBxOE}=$ Behavioral Beliefs $\mathrm{x}$ Outcome Evaluation, NBxMC=Normative Beliefs $\mathrm{x}$ Motivation to Comply, $\mathrm{CBxPP}=$ Control Beliefs $\mathrm{x}$ Perceived Power

Goodness-of-fit statistics:

$\chi^{2}=1059.4 \quad, d f=471 \quad(\mathrm{p}<.001)$

$\chi^{2} / d f=2.25$

$\mathrm{CFI}=.979$

TLI $=.975$

$\mathrm{NFI}=.963$

RMSEA $=.073$

CFI=Comparative Fit Index; TLI=Tucker-Lewis Index; NFI=Normed Fit Index; RMSEA=Root Mean Square Error of Approximation

\subsubsection{Structural Model}

The structural model was tested using AMOS. At first, the proposed model was evaluated and showed poor model fit. In order to improve model fit, the correlation between each 
independent variable (behavioral beliefs, normative beliefs, control beliefs) was added. The revised model had improved fit and resulted in close to or higher than common suggested levels (Byrne, 2001). Thus, the responses from community-dwelling elderly fit the revised model. Figure 1 and Table 4 show the results of the structural equation modeling and the overall goodness of fit $\left(\chi^{2}=1238.8, d f=515, \chi^{2} / d f=2.405, \mathrm{CFI}=.975, \mathrm{TLI}=.971, \mathrm{NFI}=.957\right.$, RMSEA=.077).

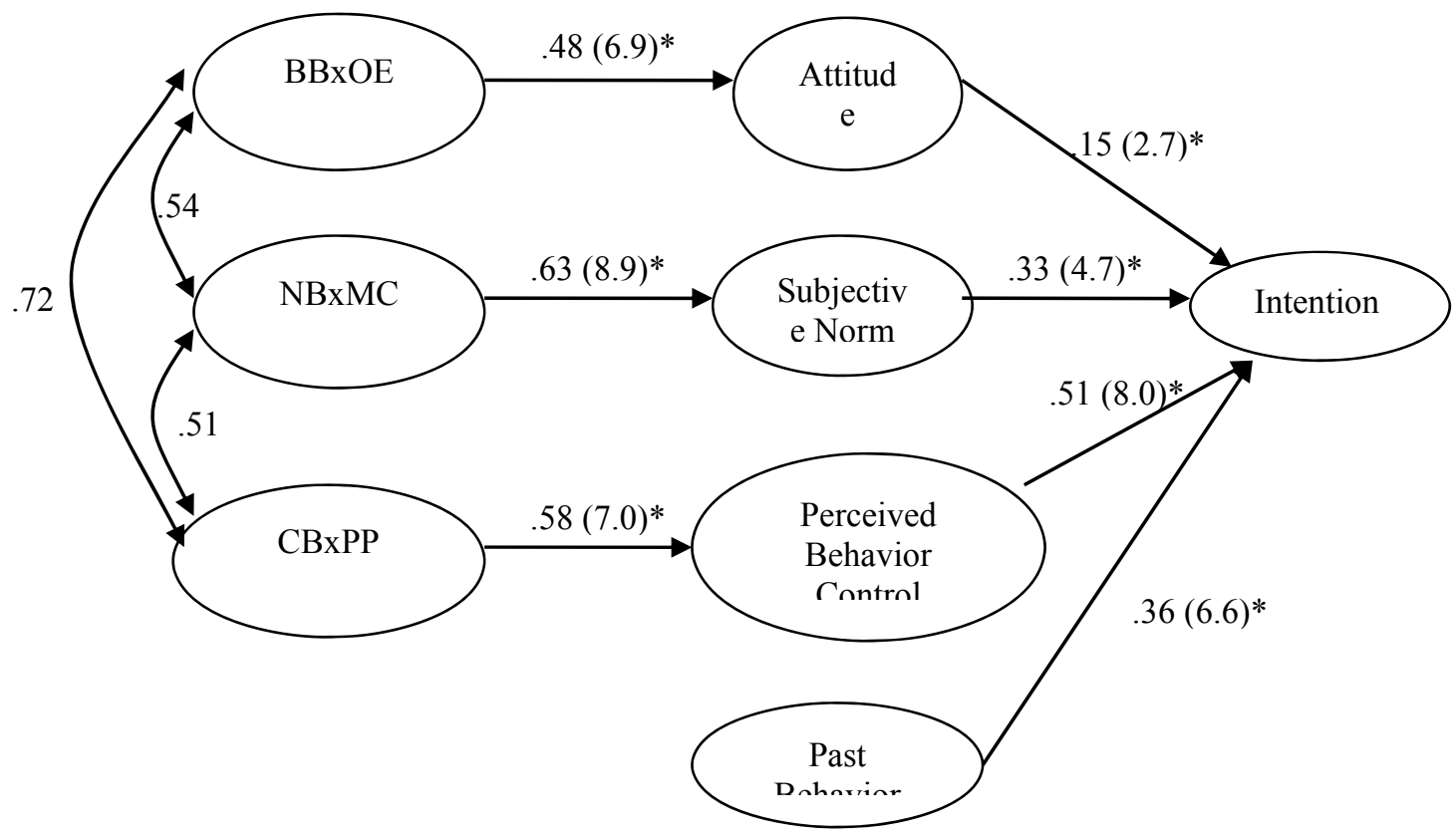

$* \mathrm{p}<.01$

Note: $\mathrm{BBxOE}=$ Behavioral Beliefs $\mathrm{x}$ Outcome Evaluation, $\mathrm{NBxMC}=$ Normative Beliefs $\mathrm{x}$ Motivation to Comply, $\mathrm{CBxPP}=$ Control Beliefs $\mathrm{x}$ Perceived Power

Figure 1. Causal Relationships of Study Factors 
Hypothesis tests were checked using the standardized path coefficient retrieved from the results of SEM. As illustrated in Table 4, t-values were significant at $\mathrm{p}<.01$ and show that all hypotheses $(\mathrm{H} 1-\mathrm{H} 7)$ were statistically supported. The path coefficient between belief measures and predictor variables showed significant positive relationships and ranged from .48 to .63 . Among all predictor variables for the TPB model, $\mathrm{PBC}$ has strongest effect on participation intention $(\beta=.51, \mathrm{t}=8.10, \mathrm{p}<.01)$, followed by past behavior $(\beta=.36, \mathrm{t}=6.64, \mathrm{p}<.01)$. Attitude has the least impact on participation intention $(\beta=.15, \mathrm{t}=2.71, \mathrm{p}<.01)$. The combination of all predictor variables, subjective norm, $\mathrm{PBC}$, and past behavior, explain $63 \%$ of the variance in participation intention.

\section{Table 4.}

Hypothesis Test: Parameter Estimate and Fit Indices

\begin{tabular}{lccc}
\hline Hypothesized Path & $\begin{array}{c}\text { Standardized } \\
\text { Parameter Estimate }\end{array}$ & $\boldsymbol{t}$ & $\boldsymbol{p}$ \\
H1: BBxOE $\rightarrow$ Attitude & .48 & 6.9 & .000 \\
H2: NBxMC $\rightarrow$ Subjective Norm & .63 & 8.9 & .000 \\
H3: CBxPP $\rightarrow$ Perceived Behavior Control & .58 & 7.0 & .000 \\
H4: Attitude $\rightarrow$ Intention & .15 & 2.7 & .007 \\
H5: Subjective Norm $\rightarrow$ Intention & .33 & 4.7 & .000 \\
H6: Perceived Behavior Control $\rightarrow$ Intention & .51 & 8.0 & .000 \\
H7: Past Behavior $\rightarrow$ Intention & .36 & 6.6 & .000 \\
$\mathrm{R}^{2}(\mathrm{BI})=.63$ & & & \\
\hline Goodness-of-fit statistics: & & & \\
$\chi^{2}=1238.8, d f=515 \quad(\mathrm{p}<.001)$ & & & \\
$\chi^{2} / d f=2.405$ & & & \\
CFI $=.975$ & & & \\
TLI $=.971$ & & & \\
NFI $=.957$ & & & \\
RMSEA $=.077$ & & & \\
\hline
\end{tabular}

Note: $\mathrm{BBxOE}=$ Behavioral Beliefs $\mathrm{x}$ Outcome Evaluation, $\mathrm{NBxMC}=$ Normative Beliefs $\mathrm{x}$ Motivation to Comply, $\mathrm{CBxPP}=$ Control Beliefs $\mathrm{x}$ Perceived Power 


\section{Discussion and conclusion}

A significant correlation was found among the belief based constructs in this study and those are not independent of one another. There is evidence of interactions among behavioral beliefs, normative beliefs, and control beliefs (Shimp and Kavas, 1984; Oliver and Bearden, 1985; Taylor and Todd, 1995; Lam and Hsu, 2004; Ryu and Jang, 2006). Some studies also report the crossover effect between belief-based structures, that behavioral beliefs might influence subjective norms or normative beliefs might affect attitude (Shimp and Kavas, 1984; Oliver and Bearden, 1985; Taylor and Todd, 1995). The present study shows that the belief constructs do indeed influence each other.

The relationship between attitude and participation intention was significant and positive, although they had the lowest parameter estimates of the four predictor variables. Seniors who hold positive feelings about the program are more willing to participate. Two possible reasons explain the weak relationship between these two factors. First, adding past behavior into the model might reduce the correlation coefficient between attitude and intention. Oh and Hsu (2001) explained that irrational or non-evaluative attitudinal factors could be absorbed if past behavior were included in the TPB model. Thus, the predictive power of past behavior increased, and the effect of attitude on intention decreased. The second reason for the weak relationship is associated with measuring attitude. Ajzen (1988) stated that the best-known multi-item instrument for directly measuring attitude is the semantic differential scale, which consists of a set of bipolar evaluative adjective pairs with each adjective pair placed on opposite ends of a five- point scale. In some cases, respondents answered only one attitude question because they assumed only one adjective depicted their attitude and left the others blank. The missing data percentage for the differential scale is much higher than with other constructs, indicating that 
participants had difficulty with this part of the questionnaire. Mullen et al.(1987) and Young et al. (1991) confirmed that reviewing the measurement items and the format for the attitude construct and making a judgment might be a conceptual challenge for older adults. The frustration of answering attitudinal questions about program participation reduces the reliability and validity of measurements. It also affects the predictive power of attitude and leads to a weak significant effect on participation intention.

Subjective norm is also important in predicting participation intention $(\beta=.33)$. Respondent intention to participate in congregate meal programs was affected by perceived social pressure from important referent groups. The results in this study support the findings of Wankel and Mummery (1993), who found that subjective norm is associated with intention to do physical activity among older adults. Its predictive power is better than attitude. Warburton and Terry (2000) reported similar findings in their study about volunteering among older adults.

PBC had a significant positive effect on participation intention. The results are consistent with Godin and Kok (1996), Povey et al. (2000), and Kim et al. (2003). Among four predictor variables in this study, PBC was the most effective predictor for participation intention $(\beta=.51)$. This indicates that when the participants had a higher degree of control or self-efficacy such as the ability to drive to meal sites, participation intention would increase. A possible reason for the causal relationship between $\mathrm{PBC}$ and intention might be facilitators and inhibitors affecting program participation. Those factors had more effects than other predictor variables on intention. For example, although older adults acknowledge the benefits of participating in congregate meal programs, they could not or did not want to eat meals in the center because they did not feel welcome. Thus, creating a welcoming atmosphere in the center is important for the meal program directors. 
Past behavior had a significant positive relationship with participation intention $(\beta=.36)$. Seniors with more previous participation experience were more willing to participate in the program in the future. The results were consistent with Ajzen's (1991) statement that when individuals perform a behavior from conscious intention, past behavior becomes a contributing factor. Program directors and site managers should focus on repeat participants and understand what attracts return visits. Word-of-mouth about program participation is important to managers and directors because positive beliefs are usually generated. Lin (1999) interviewed seventeen older adults and found that $82 \%$ of congregate meal program participants would recommend the program to their friends. Alternatively, Ponza and Wray (1990) suggested that unpleasant experiences with previous meals could be a barrier to program participation. Thus, enhancing satisfaction translates to increased participation.

This study used a convenience sample and was conducted in only one region of the Area Agency on Aging of one Midwestern state, so the findings cannot be generalized to other regions or states. Future research should use national samples to test the hypotheses. Administering the questionnaire using the "speak out loud" technique, asking participants to read and answer each question could improve clarity, eliminate unclear questions and increase study reliability and validity.

The collected samples were homogenous. In order to further enhance the feasibility of the instrument, employ it among other diverse older adults can add its ability to produce generalizable information and affirm the TPB model is capable to other communities.

Information about actual behavior was excluded from this study because of the complexity of data collection and inability to ensure anonymity. In the future, actual congregate meal program participation data should be included in the TPB model. In the present study, 
predictor variables (attitude, subjective norm, $\mathrm{PBC}$, and past behavior) accounted for $63 \%$ of participation intention. Additional factors may increase the predictive power of the TPB model. Socio-demographics could hold other determinant variables. For example, older adults from low income families might have different attitudes toward participation intention. Studies showed that $57 \%$ of congregate meal program participants were from low income households (AoA, 2006b). Comparing income groups could further explain which groups (low income versus highincome) to target when trying to increase participation intention.

This population is insightful about strengths and weakness of the program. In this tough economic climate, focusing on the customer is important for program success, which should be a top priority of directors and site managers.

\section{Implications}

This study incorporated a theoretical framework to expand our understanding of community-dwelling older adults congregate meal program participation and included past behavior in the TPB model. Oh and Hsu (2001) suggested that a simultaneous inclusion of this additional construct corresponds to recent developments in understanding human behavior. Results of our study show that past behavior has strong predictive power for participation intention, more than attitude. Including past behavior in the present model increased the predictive power of the model and makes the model a more comprehensive tool for this population.

Results of this study provide some practical implication for directors of the Area Agency of Aging, senior center managers, foodservice directors and dietitians. Following are suggestion that can help practitioners improve program participation based on the findings of this study. 
- Implementing innovative services such as congregate breakfast programs, weekend congregate meals, and congregate supper programs

- Providing transportation through public transportation, the department of aging, local civic groups, and faith groups

- Establishing a welcoming atmosphere

- Creating a comfortable physical environment

- Educating family members who can influence senior participation intention

- Implementing marketing strategies such as word of mouth

- Training staff to treat seniors as a family

Older persons provide thoughtful and insightful opinions about program participation. In this tough economic climate, focusing on the customer is important for program success and needs to be a priority of directors and site managers. Implementing effective strategies to increase participation while minimizing barriers will encourage older adults to participate, improve their nutritional intake and thus, their quality of life. 


\section{References}

Ajzen, I., 1985. From intention to action: A theory of planned behavior. In J. Kuhl \& J. Beckmann (Eds.), Action control, from cognition to behavior (pp.11-39). New York: Springer-Verlag.

Ajzen, I., 1988. Attitudes, personality and behavior. Chicago, IL: The Dorsey Press.

Ajzen, I., 1991. The theory of planned behavior. Organizational Behavior and Human Decision Processes, 50, 179-211.

Ajzen, I., 2002. Perceived behavioral control, self-efficacy, locus of control, and the theory of planned behavior. Journal of Applied Social Psychology, 32(4), 665-683.

Ajzen, I., 2006 January. Constructing a TPB questionnaire: conceptual and methodological consideration. Available online through http://people.umass.edu/aizen/pdf/tpb.measurement.pdf. Retrieved on Jun 12, 2008.

Ajzen, I., Fishbein, M., 1980. Understanding attitudes and predicting social behavior. Englewood Cliffs, NJ: Prentice-Hall, Inc.

Ajzen, I., Madden, T. J., 1986. Prediction of goal-directed behavior: Attitudes, intentions, and perceived behavior control. Journal of Experimental Social Psychology, 22, 453-474.

Albarracin, D., Johnson, B. T., Fishbein, M., Muellerleile, P.A., 2001. Theories of reason action and planned behaviors as models of condom use: A meta-analysis. Psychological Bulletin, 127(1), 142-161.

Almanza, B. A., Namkung, Y., Ismail, J. A., Nelson, D. C., 2007. Clients's safe food-handling knowledge and risk behavior in a home-delivered meal program. Journal of the American Dietetic Association, 107, 816-821.

Anderson, J. C., Gerbing, D. W., 1988. Structural modeling in practice: A review and recommended two-step approach. Psychological Bulletin, 103(3), 411-423.

Armitage, C. J., Conner, M., 2001. Efficacy of the theory of planned behavior: A meta-analysis review. British Journal of Social Science, 40(4), 471-499.

AoA, 2006a. Unofficial compilation of the older Americans Act of 1965-OAA Section330. Available online through http://www.aoa.gov/AoARoot/AoA_Programs/OAA/oaa_full.asp. Retrieved on Apr 1, 2010.

AoA, 2006b, June 1. Highlights from the pilot study: second national survey of Older Americans Act Title III service recipients. Available online through https://www.gpra.net/nationalsurvey/files/2ndhighlights.pdf. Retrieved on May 19, 2008.

AoA, 2008. FY 2006. U.S. Profile of OAA programs. Available online through http://www.aoa.gov/prof/agingnet/napis/SPR2006SPR/Profiles/u.s.pdf. Retrieved on March 10, 2008.

AoA, AGing Integrated Database (AGID), 2008a. State Program Reports (SPR) 2005-2008. Available online through http://www.agidnet.org/SPR_New.asp. Retrieved on Apr 5, 2010.

AoA , AGID, 2008b. National Survey of OAA Participants: Year 2008. Available online through http://www.agidnet.org/OAA.asp. Retrieved on Apr 5, 2010.

Bagozzi, R. P., Yi, Y., 1989. The degree of intention formation as a moderator of the attitudebehavior relationship. Social Psychology Quarterly, 52(4), 266-279.

Bermudez, O. I., Tucker, K. L., 2004. Cultural aspects of food choices in various communities of elders, Generations, 28(3), 22-27.

Bloom, B., 1964. Stability and change in human characteristics. New York, John Wiley \& Sons. 
Byrne, 2001. Structural equation modeling with AMOS. Mahwah, NJ: Lawrence Erlbaum Associates.

Carey, M., Gillespie, S., 1995. Position of the American Dietetic Association: Cost-effectiveness of medical nutrition therapy. Journal of the American Dietetic Association, 95(1), 88-91.

Chima, C. S., Barco, K., Dewitt, M. L. A., Maeda, M., Teran, J. C., Mullen, K. D., 1997. Relationship of nutritional status to length of stay, hospital costs, and discharge status of patients hospitalized in the medicine service. Journal of the American Dietetic Association, 97, 975-978.

Conner, M., \& Armitage, C. J, 1998. Extending the theory of planned behavior: a review and avenues for further research. Journal of Applied Social Psychology, 28, 15, 1429-1464.

Courneya, K. S. 1995. Understanding readiness for regular physical activity in older individuals: An application of the theory of planned behavior. Health Psychology, 14, 80-87.

Fishbein, M., Ajzen, I., 1975. Belief, attitude, intention and behavior: An introduction to theory and research. Reading MA: Addison-Wesley.

Fornell, C., Larcker, D. F., 1981. Evaluating structural equation models with unobservable variables and measurement error. Journal of Marketing Research, 18, 39-50.

Francis, J. J., Eccles, M. P., Johnston, M., Walker, A., Grimshaw, J., Foy, R., et al., 2004. Constructing questionnaires based on the theory of planned behavior. A manual for health services researchers. United Kingdom: Centre for Health Services Research, University of Newcastle. Available online through http://www.rebeqi.org/ViewFile.aspx?itemID=212. Retrieved on Jan 26, 2008.

Gallagher-Allred, C. R. Voss, A. C., Finn, S. C., McCamish, M. A, 1996. Malnutrition and clinical outcomes: The case for medical nutrition therapy. Journal of the American Dietetic Association, 96, 361-369.

General Accounting Office (GAO), 2000. Food assistance options for improving nutrition for older Americans, GAO/RCED-00-238. Available online through http://www.gao.gov/new.items/rc00238.pdf. Retrieved on Apr 15, 2008.

Godin, G., Kok, G., 1996. The theory of planned behavior: a review of its applications to healthrelated behaviors. American Journal of Health Promotion, 11, 87-98.

Gretebeck, K. A., 2000. Predicting physical activity in older adults: the theories of reasoned action and planned behavior. Unpublished doctoral dissertation, Purdue University.

Hagger, M. S., Chatzisarantis, N. L. D., Biddle, S. J. H., 2002. A meta-analytic review of the theory of reasoned action and planned behavior in physical activity: predictive validity and the contribution of additional variables. Journal of Sport \& Exercise Psychology, 24, 3-32.

Hair, J. F., Black, W. C., Babin, B. J., Anderson, R. E., Tatham, R. L., 2006. Multivariate data analysis $\left(6^{\text {th }}\right.$ ed.). Upper Saddle River, NJ: Prentice Hall.

Hausenblas, H. A., Carron, A. V., Mack, D. E., 1997. Application of the theory of reasoned action and planned behavior to exercise behavior: a meta-analysis. Journal of Sport \& Exercise Psychology, 19, 36-51.

Kendrick, O. W., Slezak, D., 1989. Nutrition program for the elderly: Participants' perception of food quality by type of food service system, Journal of Nutrition for the Elderly, 9(1), 2738. 
Kim, K., Reicks, M., Sjoberg, S., 2003. Applying the theory of planned behavior to predict dairy product consumption by older adults. Journal of Nutrition Education and Behavior, 35, 294-301.

Kuczmarski, M. F., Weddle, D.O., 2005. Position paper of the American Dietetic Association: nutrition across the spectrum of aging. Journal of the American Dietetic Association, 105, 616-633.

Lam, T., Hsu, C., 2004. Theory of planned behavior: potential travelers from China. Journal of Hospitality \& Tourism Research, 28(4), 463-482

Lee, M. J., 2005. Effects of attitude and destination image on association members' meeting participation intentions: development of meeting participation model. Unpublished doctoral dissertation, Kansas State University.

Lee, J. S., Frongillo, E. A., Olson, C. M., 2005. Conceptualizing and assessing nutrition needs: perspectives of local program providers. Journal of Nutrition for the Elderly, 24(3), 25-45.

Lin, J. C., 1999. The nutritional effects of the elderly nutrition program: Title III-C for the Menomonie congregate site meal program participants. Unpublished master thesis, University of Wisconsin-Stout.

Michael, Y. L., Berkman, L. F., Graham, A. Colditz, G. A., Kawachi, I., 2001. Living arrangements, social integration, and change in functional health status. American Journal of Epidemiology, 153(2), 123-131.

Mullen, P. D., Hersey, J. C., Iverson, D. C., 1987. Health behavior models compared. Social Science \& Medicine, 24, 973-981.

Nunnally, J. C., Bernstein, I., 1994. Psychometric theory ( $3^{\text {rd }}$ ed.). New York, NY: McGrew-Hill.

Oh, H., Hsu, C., 2001. Volitional degrees of gambling behaviors. Annals of Tourism Research, 28 (3), 618-637.

Oliver, R., Bearden, W. O., 1985. Crossover effects in the theory of reasoned action: a moderating influence attend. Journal of Consumer Research, 12(3), 324-340.

O'Shaughnessy, C., 2004. CRS report for congress-Older Americans Act Nutrition Program. Available online through http://www.nationalaglawcenter.org/assets/crs/ RS21202.pdf. Retrieved on Apr 23, 2007.

O’ Shaughnessy, C., Napili, A., 2006, December 11. The Older Americans Act: programs, funding, and 2006 reauthorization (P.L. 109-365), RL31336. Available online through http://www.ncoa.org/attachments/CRSOAAReport.pdf. Retrieved on Apr 23, 2008.

Ouellette, J. A., Wood, W., 1998. Habit and intention in everyday life: The multiple processes by which past behavior predicts future behavior. Psychological Bulletin, 124(1), 54-74.

Ponza, M., Wray, L., 1990. Final results of the elderly program study-evaluation of the food assistance needs of the low-income elderly and their participation in USDA programs. Princeton, NJ: Mathematica Policy Research, Inc.

Povey, R., Conner, M., Sparks, P., James, R., Shephered, R., 2000. Application of the theory of planned behavior to two dietary behaviors: roles of perceived control and self-efficacy. British Journal of Health Psychology, 5, 121-139.

Roelands, M., Oost, P. V., Depoorter, A., \& Buysse, A. 2002. A social-cognitive model to predict the use of assistive devices for mobility and self-care in elderly people, The Gerontologist, 42(1), 39-50.

Ryu, K., Jang, S., 2006. Intention to experience local cuisine in a travel destination: the modified theory of reasoned action. Journal of Hospitality \& Tourism Research, 30(4), 507-516. 
Shimp, T. A., Kavas, A., 1984. The theory of reasoned action applied to coupon usage. Journal of Consumer Research, 11, 795-809

Slezak, D., 2000 August 9. Evaluation of nutrition programs prepared for suburban area agency on aging and community nutrition network. Available through online http://nutritionandaging.fiu.edu/creative_solutions/Focus $\% 20$ Groups $\% 20$ Executive $\% 20 \mathrm{~S}$ ummary.pdf. Retrieved Apr 22, 2008.

Taylor, S., Todd, P., 1995. Decomposition and crossover effects in the theory of planned behavior: A study of consumer adoption intentions. International Journal of Research in Marketing, 12(2), 137-155.

Thomas, L., Ghiselli, R., Almanza., 2011. Congregate meal sites participants: can they manage their diets? International Journal of Hospitality Management, 30, 31-37.

U.S Census of Bureau, 2000. Census 2000 demographic profile highlights: selected population group: white alone. Available through online http://factfinder.census.gov/servlet/SAFFIteratedFacts?_event=\&geo_id=04000US20\& geoContext $=01000 \mathrm{US} \% 7 \mathrm{C} 04000 \mathrm{US} 20 \&$ \&street $=\&$ _county $=\&$ _cityTown $=\&$ _state $=0400$ 0US20\&_zip $=\&$ lang $=$ en\&_sse $=$ on\&ActiveGeoDiv $=\&$ useEV $\bar{V}=\& p c t x t=f p h \& p g s l=010$ $\& \_$submenuId $=$factsheet $2 \& \mathrm{ds} \_$name $=D E C \_2000 \_\mathrm{SAFF} \&$ ci_nbr $=002 \& q \mathrm{q}$ _name $=\mathrm{DEC}$ 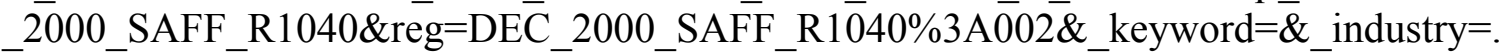 Retrieved on Nov 15, 2008.

U.S. Department of Health and Human Service (USDHHS), AoA (2009, November 19) Nutrition Service (OAA Title IIIC). Available through online http://www.aoa.gov/AoARoot/AoA_Programs/HCLTC/Nutrition Services/. Retrieved on Apr 1, 2010.

Van der Pligt, J., Eiser, J. R., 1984. Dimensional salience, judgment and attitudes. In J. R. Eiser (Ed.), Attitudinal judgment (p.161-177). New York, NY: Springer-Verlag.

Wankel, L. M., Mummery, W. K.,1993. Using national survey data incorporating the theory of planned behavior: implications for social marketing strategies in physical activity. Journal of Applied Sport Psychology, 5, 158-177.

Warburton, J., Terry, D. J., 2000. Volunteer decision making by older people: A test of a revised theory of planned behavior. Basic and Applied Social Psychology, 22(3), 245-257.

Young, H. M., Lierman, L., Powell-Cope, G., Kasprzyk, D., Benoliel, J. Q., 1991. Operationalizing the theory of planned behavior. Research in Nursing and Health, 14, 137-144. 